\title{
In what context does context matter? An ERP study of sentence processing in Brazilian Portuguese
}

\author{
Em que contexto o contexto importa? Um estudo de ERP com sentenças \\ em português brasileiro
}

\author{
Marije Soto \\ Aniela Improta França \\ Juliana Novo Gomes \\ Universidade Federal do Rio de Janeiro - Rio de Janeiro - Rio de Janeiro - Brasil \\ Aline Gesualdi Manhães \\ Centro Federal de Educação Tecnológica Celso Suckow da Fonseca (CEFET/RJ) - Rio de Janeiro - Rio de Janeiro - Brasil
}

$\diamond$

\begin{abstract}
The N400 component is the most famous ERP component in linguistic studies. It has a negative amplitude peak at approximately $400 \mathrm{~ms}$ after stimulus onset. It has been reported in the last 30 years in connection with the attempt of the verb to integrate its complement. It is also related to lexical access in general and to participants' response when incoming words do not match predictable candidates in online processing. This study focuses on the sensitivity of the N400 to early information from outside of the verb-complement scope, (contained in an adjunct in the left periphery of the sentence). Using supporting adjunct information as a condition, this study tries to unveil the sensitivity of the N400 to data that is not part of the core structure of the event. Our hypothesis is that the information in the adjunct position is not taken into account in the same time-frame of the event and, indeed, the analyses involving several pre-tests with varying SOAs, showed no difference in the N400 component for sentences with relevant adjunct information when compared to those with irrelevant adjunct information.
\end{abstract}

Keywords: N400; ERPs; Context; Syntax-semantic interface; Adjunct-complement dichotomy

Resumo: O componente N400 é o ERP mais famoso em estudos eletrofisiológicos da lilnguagem. O N400 tem amplitude negativa aproximadamente aos $400 \mathrm{~ms}$ após estímulação. Nos últimos 30 anos, o N400 tem sido relacionado ao esforço de o verbo de integrar o seu complemento. Ele também está relacionado com o acesso lexical e à frustação da previsibilidade do falante ao antecipar a próxima palavra durante o processamento online. Procuramos explorar a sensibilidade do N400 à informação precoce fora da arena verbo-complemento (um adjunto na periferia esquerda da sentença). Utilizando informação acessória, como condição, este estudo tentará desvendar a sensibilidade do N400 para dados que não são parte do evento. A hipótese é que as informações na posição de adjunto não seriam levadas em conta no mesmo espaço de tempo da informação do evento. De fato, as análises, que envolveram vários pré-testes com diferentes SOAs, não mostraram diferença nos parâmetros do N400 para frases com informações relevantes no adjunto comparados àqueles com informação irrelevante.

Palavras-chave: N400; ERPs; Contexto; Interface sintaxe-semantica; Dicotomia adjuntocomplemento 


\section{Introduction}

A success story that has attracted the attention of scientists from several neuroscience backgrounds is the Event Related brain Potential (ERP) ${ }^{1}$ and its main component, the $\mathrm{N} 400^{2}$. As so many great discoveries, it was found 'by accident' in 1978, when psychologists Kutas and Hillyard were carrying out an oddball paradigm $^{3}$ study, but instead of using the customary simple visual stimuli, they decided to try out linguistic stimuli. They anticipated that unpredictable sentence endings (e.g. He spread the warm bread with socks) would yield a P300 effect, which is the usual response for the oddball paradigm. Much to their surprise, they found a later component, a negative peak at about $400 \mathrm{~ms}$ after word onset, which became known as the N400. The high amplitude of the N400 started being associated loosely with the difficulty of integrating semantically implausible words in sentences (Figure 1).

Although the component has since then been found with stimuli other than language, for example, with images (for a review cf. KUTAS and FEDERMEIER, 2011), a violation of melody expectation will not result in an N400 effect (KUTAS and VAN PETTEN, 1988). Thus, the mysterious specificity of the effect and the possibility of testing hypotheses relating the serial nature of language processing of its surface form to its underlying hierarchical structure, owing to the quintessential online nature of ERP measures, quickly drew an varied array of researchers into EEG-ERP experiments with linguistic stimuli. Due to the heterogeneous background of these scientists, the variety of research methods that were adopted led to experimental and analytical biases worthy of investigation.

From the start, the exact nature of the N400 has been a topic of hard debate. Granted the summed nature of the ERP components ${ }^{4}$, the N400 could either be the consolidated result of multiple underlying computations, or a reflex of one of several computations in a row depending on the processing stage (KUTAS and FEDERMEIER 2011; LAU, PHILLIPS and POEPPEL 2008).

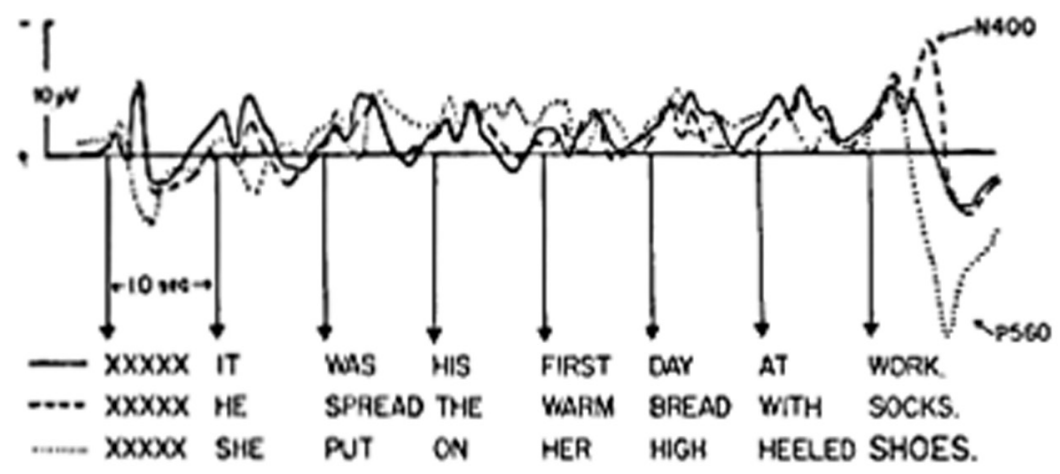

Figure 1. The first N400 ERP. Extracted from the original paper (KUTAS, M. and HILLYARD, 1980, p. 203). Note that the incongruous condition yields a high amplitude N400; the congruous condition yields a low amplitude N400; and the condition with the abnormal capital letters in the last word yield another effect of opposing polarity (positive, plotted downward) and longer latency (app. 560ms).

\footnotetext{
1 Event Related brain Potentials are measures extracted from continuous EEG recordings in which stimulus presentation onset is coupled in time with brain responses so that the neurophysiological responses can be robustly related to stimuli. Segments are added and averaged per experimental condition so that they may be compared for condition effects. This is measured by comparing amplitudes (in voltage) and latencies (moment of maximum peak in $\mathrm{ms}$ ) in a given time interval.

2 The N400 component is one of the most robustly replicated ERP signature and also the main linguistic ERP component to be studied. It is a negative amplitude peak (usually plotted upwards) that rises approximately 400ms after stimulus onset.

3 The Oddball Paradigm is a target-detection task. Participants are asked to respond by pressing a button whenever they see visual or auditory stimuli that occur infrequently and irregularly within a standard series. As such, the experimenter shows a series of symbols a repeated number of times until the participant becomes habituated to the pattern. A pattern might
}

\begin{abstract}
consist of three black circles followed by two yellow squares. Suddenly, after the standard is established a green triangle appears in between the black circles and the yellow squares. This pattern breaking detection is related with a positive brain potential that rises at $300 \mathrm{~ms}$ post diverging stimulus: the P300.

4 The EEG signal is the direct result of the activity of a given neuronal population, but from the signal captured by electrodes from the outside (the scalp), there is no unequivocal way to determine the generator source of the signal, nor whether it is the result of two or more populations firing at once or one after the other. Also, intervening brain tissue (between generator source and scalp) and varying angles of the position of neurons in the gyrating layer of the cortex affect the signal in sometimes unpredictable ways. So in analysing ERPs, one should keep in mind that any data point in time represents the sum of all potential values and brain wave frequencies that make up a complex EEG signal (LUCK, 2005).
\end{abstract}


Indeed the ERP methodology has brought much evidence that pure linguistic information has an immediate effect on processing streams. Manipulations of word category information, for example, affect ERP signals as soon as $40-90 \mathrm{~ms}$ after word onset, and at $120-150 \mathrm{~ms}$, if there is a category violation (e.g. I washed my dirty handed, a verb where a noun is expected, see FRIEDERICI, 2012 for reviews).

The N400 effect can also be manipulated by strict linguistic variables, examples of which are morphological priming (e.g. TEACHER-teach) dissociated from orthographic or semantic priming with both masked and unmasked priming (FRANÇA et al., 2008; GOMES, FRANÇA, 2013), and effects of syntactic complexity, such as Wh-questions or pronominal referencing (e.g. He took the knife and he's going to sharpen/cut it, noting that, in Portuguese, pronominal references agree in gender, strengthening the violation, FRANÇA, SOTO, GESUALDI, 2012).

Given the evidence of syntactic involvement in the the processes underlying the N400, generally thought to reflect semantic processess (FEDERMEIER et al., 2013; FRANKLIN et al., 2007; KUTAS and FEDERMEIER 2011; LAU et al., 2009), the phenomenon was placed at the heart of the syntax-semantics interface research. In that regard, the response to a target word (such as tea vs. teepee in the sentence su Joe drank the tea vs. teepee ('João bebeu o chá vs. chalé', FRANÇA et al., 2002)) reflects the moment at which the verb (or any other complement projecting item, such as a preposition) attributes a theta role, marked morphosyntactically by case, thus licensing (or failing to do so, in the case of violation) its argument(s).

Given the nature of these operations, we might suppose there is micro syntactic bootstrapping involved that allows for the semantic interpretation of linguistic expressions, because the syntactic structuring of objects (complements or internal arguments) and subjects is closely linked to theta role assignment (for instance, the agent role for the subject position and the theme role for object position). Moreover, lexical representations of verbs may contain not only theta-grid information (number of arguments, their category, and positions projected by the verb), but also minimal semantic features as constraints for their arguments, such as [+drinkable] or [-animate]. In this view, the N400 may reflect basic, unavoidable combinatory processes between a verb (or preposition) and its complement and should not be affected by other informational content coming from context outside of the realm of predicators and their arguments.

Nevertheless, some studies do attest to the influence of different levels of context. For example, with sentences such as They wanted to make the hotel look more like a tropical resort. So along the driveway they planted rows of ... palms vs. pines vs. tulips, Federmeier and Kutas (1999) studied the effect of sentential context on endings varying in improbability. They found a modulation of the effect in which the word tulips shows the highest amplitude due to incompatibility with preceding sentential context (characterized by tropical resort and driveway); whereas pines, equally improbable, showed intermediate amplitudes, according to the authors due to its semantic relatedness to palms (i.e. also a tree), the preferred ending. This would illustrate what is known as surface reading: rather than going deep into the hierarchical structure embedded within the sentence, a few key semantic features taken from individual word roots are interpreted to construct a sort of surface reading. Other readings may derive from this but are not thought to bootstrap processing.

Another study by Hagoort et al. (2004), manipulated conceptual knowledge vs. world knowledge, where conceptual violations (Dutch trains are sour) yielded similar N400 effects as world knowledge violations (Dutch trains are white, when in reality in Holland all trains are yellow). These examples are among many that indicate that higher level information and surface reading processing might affect the N400. If this is true, then either higher level information is available during syntactic processing, which would prove hypotheses claiming strict serial and modular processing streams to be incorrect, or that such N400 effects reflect post syntactic processes.

Despite these results, some methodological reservations might be expressed. For example, in the Federmeier and Kutas (1999) and Kutas \& Federmeier (2000) studies, rather than attributing amplitude modulations to constraining context of the sentence as a whole, an alternative explanation could take into consideration the influence of a more immediate (syntactic-semantic) context in which there is perhaps also a gradual plausibility of the lexical item commonly following "rows of..." Also, the basis of comparability of their stimuli is based on cloze measures. ${ }^{6}$ That is, a

\footnotetext{
For example, as an estimate for possible frequency of coocurrence of 'row of...', Google hits show this gradual plausibility: rows of palms 441.000; rows of pines: 175.000; rows of tulips, for .com sites.

6 Cloze tests are thought to say something about the probability of a lexical item to appear in a given (sentential) context. It was initially developed by Taylor in 1958 as a way to measure effective communication, and it was largely applied in the educational realm, for training and testing comprehension, reading and vocabulary knowledge (SADEGI, 2008). In language studies, cloze tests have been used to determine the 'degree of fit' (FEDERMEIER et al., 2007) of a particular item in a given sentence. The degree of fit is then measured according to the frequency with which it was used to fill out a blank in a given sentence, and expressed as cloze probability in a percentage of the total number of blanks filled out. The best fit, or 'best completion', is thus the item with the highest cloze probability. In psycholinguistic as well as neurolinguistic studies, cloze probability is associated with facilitated cognitive processing to such a point that the level of cloze probability for congruous sentences is directly correlated by measures, be they reaction times or neurophysiological responses such as the N400 (FEDERMEIER et al., 2007; JORDAN and THOMAS, 2002; RAYNER and WELL, 1996).
} 
percentage representative of how many times a given word was filled in a given slot in a given sentence by participants is supposed to correlate with how easy or difficult that word is accessed during online sentence processing. Considering that this correlation mostly bears out for studies that use long SOAs ${ }^{7}$, it might well be that cloze measures reflect more conscious processing, but perhaps not faster or more automatic lexical access. After all, conditions of cloze completion are barely comparable to those of online sentence processing, for which there is no total access to the entire scope of a sentence at once (we receive information linearly, and process it incrementally), nor time to consciously think of the most logical word among many options. Even though we may instruct participants to write down whichever word comes up first, 'without thinking too much', it is essentially different from gathering evidence of the process as it is unfolding online - in less than half a second.

\section{The Experimental Hypothesis}

The question we entertain here - "In what context does context matter?" - is not simply whether the N400 effect exists as a consequence of context manipulation, but whether it reflects the default, first and preferred strategy at natural speech rates. Our hypothesis is that, with a fast SOA, context will not matter much because we should be able to capture a subtle firsthand computation readily integrating the verb with the complement. Our second hypothesis is that this firsthand computation would then be the structural basis on which to pose accessory or contextual elements afterwards, even when that contextual information comes from an adjunct that is placed prior to the verb in the surface sequence of the sentence.

\section{Materials and methods}

\section{Stimuli}

Each participant saw 240 sentences: 120 distractors, 30 sentences with and 30 without supporting context, and 60 incongruous sentences of which 30 with and 30 without supporting context. Sixty of the distractor sentences were incongruous, to balance YES/NO answers for the incongruence judgment task. Four versions were compiled in which target words were repeated for all conditions except for incongruous sentences (Table 1).

For each version, 2 pseudorandomizations were created, such that there was an even distribution of conditions in the list. During the study, 8 different lists ( 4 versions $\times 2$ randomizations) were distributed among all participants. The stimuli were also controlled for length (average of 9 words (7-11) and for frequency ${ }^{8}$.

To guarantee participants' attention, they were asked to judge whether the sentences made sense or not by pressing a button as soon as the screen presented them with the word RESPONDA ("answer") (i.e. congruence judgment).

\section{Stimulus Presentation}

Participants first saw four blocks of sentences $(4 \times 60$, a total of 240 sentences $)$ in pseudorandomized order; in between blocks there was an interval, the duration of which was determined by the participant. The presentation was programmed and presented with Eprime software, version 2 (developed by Psychology Software Tools, Inc.). Sentences were presented segmented into inseparable linguistic constituents (1-3 words). For presentation rates, see Table 2 .

Table 1. Stimuli per condition

\begin{tabular}{lccc}
\hline \multicolumn{1}{c}{ Condition } & Context & Congruence & Stimulus example (n=30 for each condition) \\
\hline 1: CSC & supportive & congruous & Até sem capacete, João dirige $\uparrow$ a moto feito louco* \\
2: CNSC & non-supportive & congruous & Todos os dias, João dirige $\uparrow$ a moto feito louco \\
3: ISC & supportive & incongruous & Até sem capacete, João dirige $\uparrow$ a pera feito louco \\
4: INSC & non-supportive & incongruous & Todos os dias, João dirige $\uparrow$ a pera feito louco \\
\hline
\end{tabular}

Abbreviations: congruous supportive-context (CSC); congruous non-supportive context (CNSC); incongruous supportive-context (ISC); incongruous non-supportive context (INSC).

* The translation of the stimuli in English: Até sem capacete, João dirige $\uparrow$ a moto feito louco: 'Even without a helmet, João drives the motorcycle like a madman', Todos os dias, João dirige $\uparrow$ a moto feito louco: 'Everyday, João drives the motorcylce like a madman'; Até sem capacete, João dirige $\uparrow$ a pera: Even without a helmet, João drives the pear'; Todos os dias, João dirige $\uparrow$ a pera:'Everyday, João drives the pear'.

\footnotetext{
Stimulus-onset asynchrony (SOA) is a measure used in experimental science. SOA refers to the amount of time between the start of one stimulus and the start of another subsequent stimulus. This time window can be manipulated experimentally to determine its effects on other dependent measures such as reaction time or brain activity.

8 Frequency is measured by Google hits for . $b r$ sites. It is perhaps not an ideal but an acceptable indication of surface frequency in the absence
}

\footnotetext{
of large accessible corpus with the appropriate information codification. Google hits filter out infrequent words such as drupa ('blossom') with 24.500 hits vs. flor ('flower) with $10,400.000$ hits or coturno (lumberjack) 955.000 hits vs. bota ('boot') with 5,360.000 hits. Also, the fact that items are repeated for conditions spreads eventual bias brought on by frequency differences.
} 
Table 2. Presentation Protocol

\begin{tabular}{|c|c|c|c|c|c|c|c|c|c|c|}
\hline \multicolumn{11}{|c|}{ Presentation Protocol ERP Experiment? sentence task } \\
\hline Presented & + & Até sem capacete & (blank) & João & $(\ldots)$ & a moto & (blank) & feito louco & (blank) & Responda \\
\hline Action & & & & & & Target & & & & Congruent Y/N? \\
\hline Timing (ms) & 1500 & 300 & 100 & 250 & (...) & 250 & 100 & 250 & 600 & 1500 \\
\hline
\end{tabular}

\section{Procedures}

Participants were placed in a an airconditioned room (ACESIN Lab at UFRJ) in a comfortable chair, approximately $100 \mathrm{~cm}$ from an 19 inch screen. First, head circumference was measured in order to determine which cap size $(54,56$ or $58 \mathrm{~cm})$ was to be used (ActiCAP, sold and developed by BrainProducts). Then forehead and mastoid regions were cleaned with alcohol. The cap was placed so that $\mathrm{Cz}$ was centralized on the head where the longitudinal and latitudinal lines cross. The velcro band underneath the chin was adjusted and strapped, so the cap fit snugly, without causing discomfort to the participant. Then 64 active electrodes were placed in the appropriate holes according to a 10-10 set-up 9 (see Figure 2), with mastoid reference electrodes.
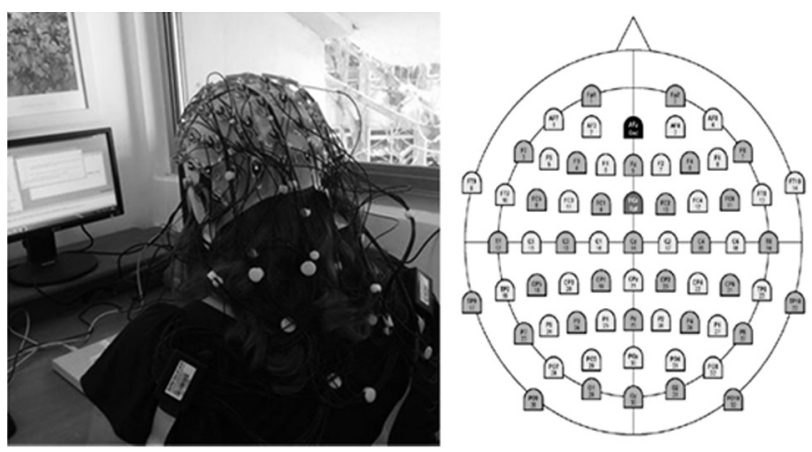

Figure 2. On the left, a participant with the electrode cap on, taking the test. On the right the scalp distribution of the eletrodes

A special electrolyte conductive gel was injected in the small openings on the side of the electrodes to

\footnotetext{
9 The 10-10 setup is based on the 10-20 system was initially developed by Jasper (1958), and it describes the positioning and naming of electrodes in a system where electrodes are placed at 10 or $20 \%$ intervals along latitude and longitude lines running over the skull (in this case, all electrodes are placed at $10 \%$ intervals).. The 'equators' (the middle longitudinal and latitudinal lines) go from the nasion (between eyes, top of the nose) to the inion (bone felt at the back of the head), and from the left pre-auricular point to the right pre-auricular point. Along parallel running longitudinal and latitudinal lines, the distances between one extreme point to another are divided into 10 and $20 \%$ intervals along which electrodes are placed. Electrodes are named for the cortical area they 'cover', F, C, T, P and $\mathrm{O}$ (or a combination thereof, such as, $\mathrm{POz}$, for example,, and numbered according to position $1,2,3$, etc. and hemisphere (even=R, uneven=L) (LUCK, 2005).
}

ensure conductivity. These active electrodes have Ag/ $\mathrm{AgCl}$ sensors, which allow for the precise measuring of impedance. Impedance was kept at a minimum, varying from 0 to $30 \mathrm{kOhms}$. Participants were instructed to remain as still as possible, keeping blinking, frowning, swallowing and shuffling of feet to a minimum. The task was explained to participants, after which they did a short training session to get used to pace and to verify task comprehension. Participants' judgments were recorded by pressing with one of two fingers of the right hand either a red or a green button on a button box. The position of the green and red buttons, destined for YES and $N O$ responses, was swapped for each participant.

Preparing the participant and recording the data took about 90 minutes. The experiment took place with low lighting, at room temperature and in silence.

\section{Participants}

Twenty-one university students participated in the study (fem $=11$ ), distributed evenly over 4 versions, average age 22 years old, all right-handed, with normal or corrected-to-normal vision.

\section{Recording set-up}

For EEG recording ActiCHamp equipment by BrainProducts was used. The active electrodes were connected to the ActiCHamp amplifier that digitized the analogue signal captured by the electrodes. From the computer that handled the stimulus presentation, the presentation program sent pulses via the parallel port, marking stimulus onset for posterior segmenting of the continuous EEG signal. These pulses (also named triggers) were simultaneously recorded on a separate channel along with the other 64 electrode channels. During acquisition, the signal was filtered with a $100 \mathrm{~Hz}$ low-pass and $0,01 \mathrm{~Hz}$ high-pass filter. EEG was referenced on-line to left and right mastoid channels. Data were digitized at a $500 \mathrm{~Hz}$ sample frequency by a 24-bit analog-to-digital converter.

The ActiCHamp device was connected to another computer with a software to configure recording parameters (sample frequency, reference, etc.). The program Pycorder is an open source acquisition program which records and saves the digital signal for later 
processing. The software is developed by BrainVision and is compatible with the program used for further processing, Analyzer (also by BrainVision).

\section{Processing and statistical analysis}

The pulses sent via parallel port were converted into strings (S 1, S 2, etc.) depending on the experimental condition of the stimulus shown. This enabled the program to separate the continuous EEG signal into epochs, which in this study were segments of $1200 \mathrm{~ms}$, starting $200 \mathrm{~ms}$ before and ending $1000 \mathrm{~ms}$ after trigger markers. During segmentation, a baseline correction was carried out, by which activation from all segments $200 \mathrm{~ms}$ to $0 \mathrm{~ms}$ before stimulus onset are subtracted from the total signal, under the assumption that the pre-stimulus signal contains general noise unrelated to the target activity. By subtracting such noise, the signal of interest was cleared of default noise and the pre-stimulus period was 'normalized' to an approximate zero voltage activity level. After these steps, the segmented signals were manually inspected for artifacts, such as eyeblinking, frowning, swallowing and other distorted signals (due to loose electrodes, crosstalking between electrodes, etc.). Finally, the signal was filtered by a lowpass Butterworth filter of $30 \mathrm{~Hz}$.

After these procedures the segmented signals were averaged separately for each condition as well as participant so that conditions could be compared in graphs. Participants with outlier values (mean + or $-3 *$ SDEV) in every condition or over $30 \%$ epoch rejection after artifact inspection were left out of the grand average - the result of averaged ERPs from all participants.

For statistical analysis, from each participant's ERP, mean amplitude values (in $\mu \mathrm{V}$ ) and amplitude peak latencies (in ms) were generated and measured within a predetermined time interval $(100-300 \mathrm{~ms} ; 300-500 \mathrm{~ms}$; $500-800 \mathrm{~ms})$. The time intervals were chosen based on findings in literature that the component of interest (N400) occurs between 350 and 500ms (KUTAS, 2011). Choosing an ample time interval (300-500ms) avoids data-driven bias, and captures the broad negativity that generally characterizes responses to linguistic stimuli. Mean amplitudes are averages of all $\mu \mathrm{V}$ data points in the predetermined time interval, while peak latencies reflects the moment (in ms) of the highest peak within the predetermined time interval, as measured by the peak measuring algorithm of the processing platform (Analyzer 2.0).

The main advantage of using a substantial number of channels is that, based on anatomical proximity, the data of several channels can be pooled, so as to increase data points and thus statistical power. To this effect, both of these dependent measures, that is, the voltages and the latencies, were analyzed with repeated measures analyses of variance (ANOVA) within 12 six-channel-groups or so-called Regions of Interest (ROIs), chosen on the basis of anatomic proximity. For instance, along the mid-line, they were: Frontal (F1, F2, FC1, FC2, FCz and Fz); Central (C1, C2, CP1, CP2, CPz and C), Parietal (CP1, $\mathrm{CP} 2, \mathrm{CPz}, \mathrm{P} 1, \mathrm{P} 2$, and $\mathrm{Pz})$, and Occipital (O1, O2, Oz, $\mathrm{PO} 3, \mathrm{PO} 4$, and $\mathrm{POz}$ ).

A three-way ANOVA model (Type III) was used and the experimental variables, as well as ROI, and hemisphere were included for analysis. Statistical analysis was carried out in SPSS (version 20). Sphericity is assumed, unless significant for Mauchly's Test of Sphericity, thus Greenhouse Geisser corrected values are presented.

\section{Results}

From 21 results, 17 were processed; 3 were rejected due to low signal to noise ratios (due to high frequency noise and eye blinking artifacts etc.) which lead to an epoch rejection of over $30 \%$. One participant was excluded from the analysis due to technical problems during recording.

Figures 3,4 and 5 show a sample of the plotted waves per condition and per ROI on midline regions, and left and right hemispheres (positions of the electrodes):

In the ERP graphs, we can see that wave patterns are roughly similar for all conditions with two major peaks: the first in the $0-300 \mathrm{~ms}$ interval, and the second in the 300$500 \mathrm{~ms}$ window. In the negative peaks, main effects for the two variables: contextualization (supportive vs. nonsupportive) and congruence (congruous vs. incongruous) are visible.

As to the statistical analysis, we will focus here on the main time interval: from 300 to $500 \mathrm{~ms}$ and on mean amplitude measures. In this window there was a strong main effect for congruence, with $\mathrm{F}(1,18)=17,157$, $p=0,001$, which tells us that the experiment worked fine. The N400 is a robust measure for incongruence and this finding signals that the measures were realible.

Most importantly there was no main effect for contextualization, $\mathrm{F}(1,18)=0,419, \mathrm{p}=0,526$, and no interaction between the two variables $(\mathrm{F}(1,18)=0,589$, $\mathrm{p}=0,453)$. This suggests that the control effect of congruous vs. incongruous sentences is similar for supportive and non-supportive context frames. There is also no specific interaction between the variables and the ROIs $(\mathrm{ROI} \times$ Congruency: $\mathrm{F}(12,216)=0,820$, $\mathrm{p}=0,522$; ROIxContext: $\mathrm{F}(12,216)=1,056, \mathrm{p}=0,390$; ROIxContextxCongruency: $F(12,216)=1,176, p=0,329)$. However, ROI as a variable has high significance, with $\mathrm{F}(12,216)=7,117, \mathrm{p}=0,001$, which indicates that 

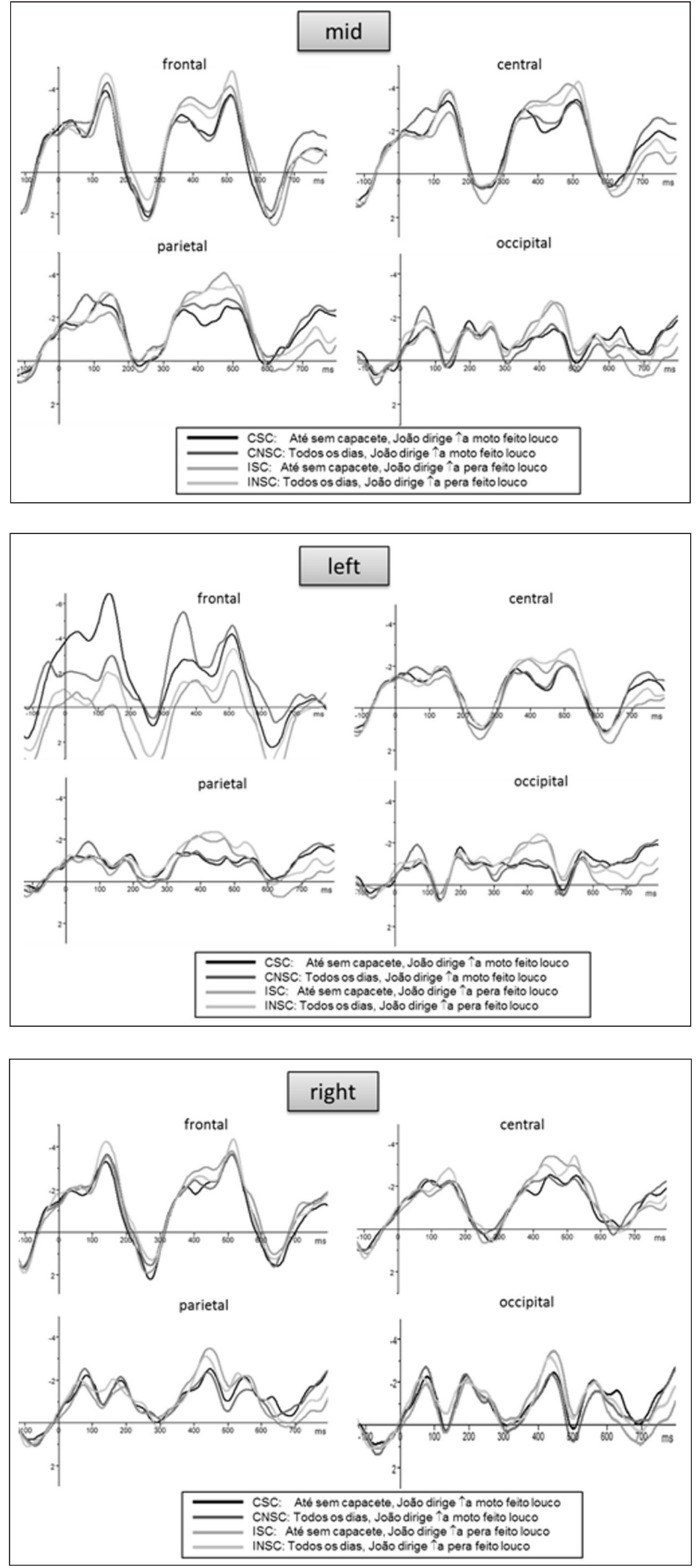

Figure 3. The sample of the plotted waves per condition and per ROI in the midline region

Figure 4. The sample of the plotted waves per condition and per ROI on the left hemisphere

Figure 5. The sample of the plotted waves per condition and per ROI on the right hemisphere 
neurophysiological responses vary greatly depending on the measured area, although they do not necessarily correlate with one specific variable. When we investigate contributions of ROIs per hemisphere (frontal, central, parietal, occipital $\times$ left, right), we see an interaction $F(3,48)=2,931, p=0,043$. This reflects that similar ROIs (e.g. left and right frontal ROI) present different effects with regard to the manipulated variables depending on the hemisphere.

\section{Mean Amplitudes}

In Graph 1, we can see amplitude measures (in $\mu \mathrm{V}$ ) for the 12 selected ROIs, comparing control effect, i.e. congruous vs. incongruous sentences, for the supportive context sentence frame. There is a constant trend of lower amplitudes for congruous sentences in comparison to higher amplitudes for incongruous sentences; however, this trend is reflected in statistic difference only for midline regions: frontal: CSC: $-20,19(3,758) \mu \mathrm{V} v$ vs. ICSC: $-27,98(5,661) \mu \mathrm{V}, \mathrm{p}=0,042$; parietal: CSC: $-18,70(4,09)$ $\mu \mathrm{V}$ vs. ICSC: $-29,69(4,72) \mu \mathrm{V}, \mathrm{p}=0,007$, and near statistical difference for central: CSC: $-23,419(3,20)$ $\mu \mathrm{V}$ vs. ICSC: $-29,15(5,79) \mu \mathrm{V}, \mathrm{p}=0,093$; and occipital: CSC: $-8,002(2,75) \mu \mathrm{V}$ vs. ICSC: $-14,188(2,89) \mu \mathrm{V}$, $p=0,077$. There is also significance for the occipital region on the left hemisphere: CSC: $-7,37(2,68) \mu \mathrm{V}$ vs. ICSC: $-14,53(2,77) \mu \mathrm{V}, \mathrm{p}=0,03$, and near statistical significance for parietal and occipital regions on the right hemisphere, respectively: CSC: $-13,75(2,89) \mu \mathrm{V}$ vs. ICSC: $-19,83(3,62) \mu \mathrm{V}, \mathrm{p}=0,067$, and CSC: $-9,88(2,47)$ $\mu \mathrm{V}$ vs. ICSC: $-15,15(3,25) \mu \mathrm{V}, \mathrm{p}=0,074$. These results reflect a stronger effect for congruence for regions on the midline, with an emphasis on parietal regions, as well as occipital regions, more generally (also for left and right hemispheres).
Graph 1. Mean Amplitudes for congruous vs. incongruous stimuli with supportive context

Graph 2. Mean amplitudes for congruous vs. incongruous stimuli without supportive context
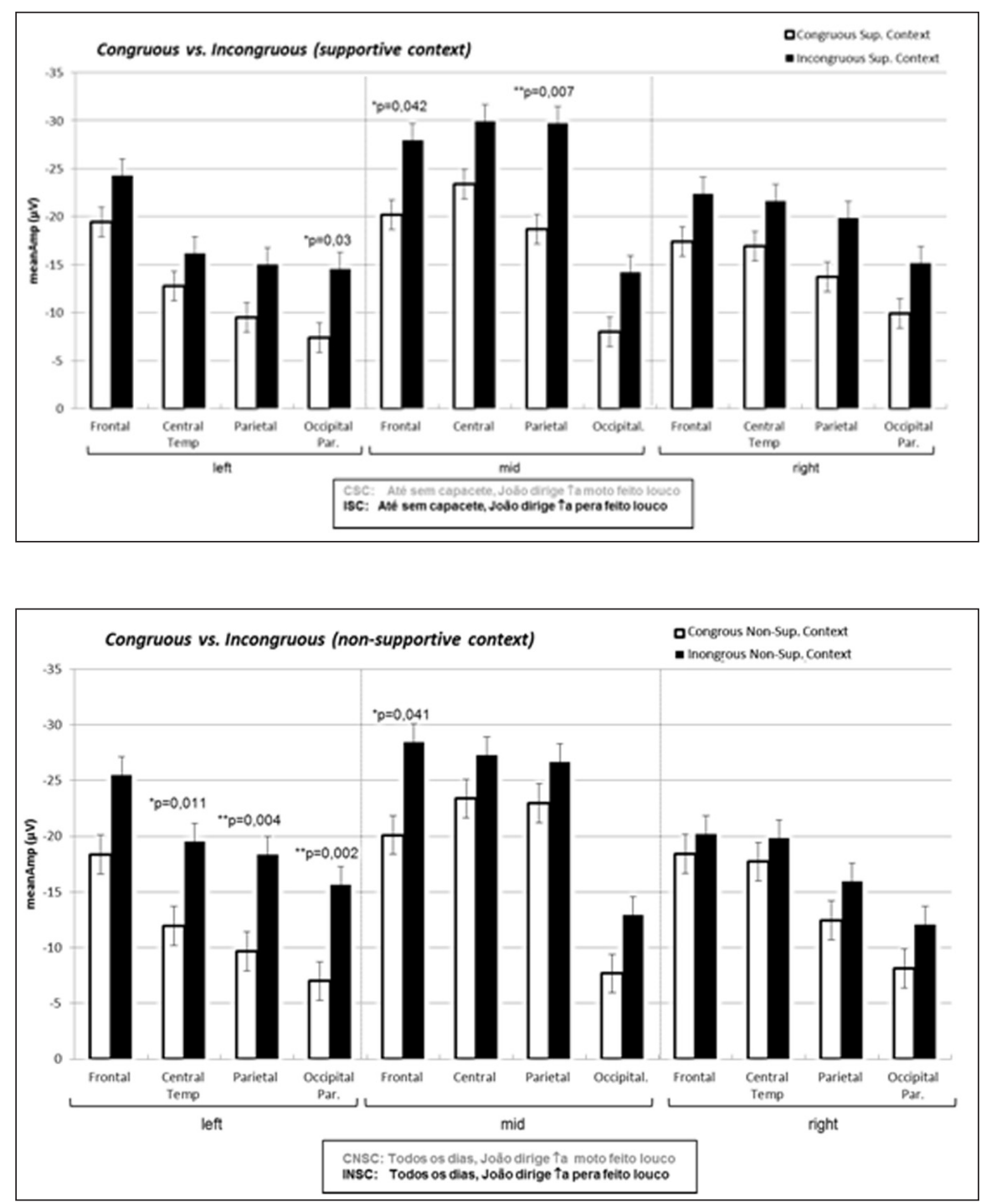
A slightly different account holds for the comparison of congruous and incongruous sentences with a nonsupportive context frame. For these type of stimuli, the congruency control effect is much stronger for regions on the left hemisphere: central temp.: CNSC: $-11,94(2,92)$ $\mu \mathrm{V}$ vs. INSC: $-19,51(2,72) \mu \mathrm{V}, \mathrm{p}=0,011$; parietal: CNSC: $-9,68(2,21) \mu \mathrm{V}$ vs. INSC: $-18,33(2,23) \mu \mathrm{V}$, $\mathrm{p}=0,004$; occipital par.: CNSC: $-7,00(2,10) \mu \mathrm{V}$ vs. INSC: $-18,62(1,85) \mu \mathrm{V}, \mathrm{p}=0,002$. There is also significance midfrontally: CNSC: $-20,09(5,41) \mu \mathrm{V}$ vs. INSC: $-28,42(5,19)$ $\mu \mathrm{V}, \mathrm{p}=0,041$; and near significance for the mid-occipital region: CNSC: $-7,67(2,44) \mu \mathrm{V}$ vs. INSC: $-12,91(2,59) \mu \mathrm{V}$, $\mathrm{p}=0,096$.

In graph 3 , we can observe the zero effect for context $(\mathrm{F}(1,18)=0,419, \mathrm{p}=0,526)$ for congruous sentences, given that there is no significance between the conditions supportive and non-supportive context in any of the ROIs, nor any near significance.
Similarly, for the incongruous sentences, there was no significance in the comparison of supportive vs. nonsupportive context for any of the ROIs, nor any near significance.

\section{Peak Latency}

Peak latency analysis did not yield any main effects for the variables congruency nor context.

\section{Discussion and Conclusions}

According to our hypothesis, we expected to see no modulation of the N400 effect due to contextualization in the preceding adverbial adjunct, especially not at fast SOA rates. Indeed, statistical analyses indicated no mean effect for context in the mean amplitude measures $(F(1,18)=17,157, p=0,001)$, and also not in
Graph 3. Mean amplitudes for supportive vs. non supportive congruous stimuli

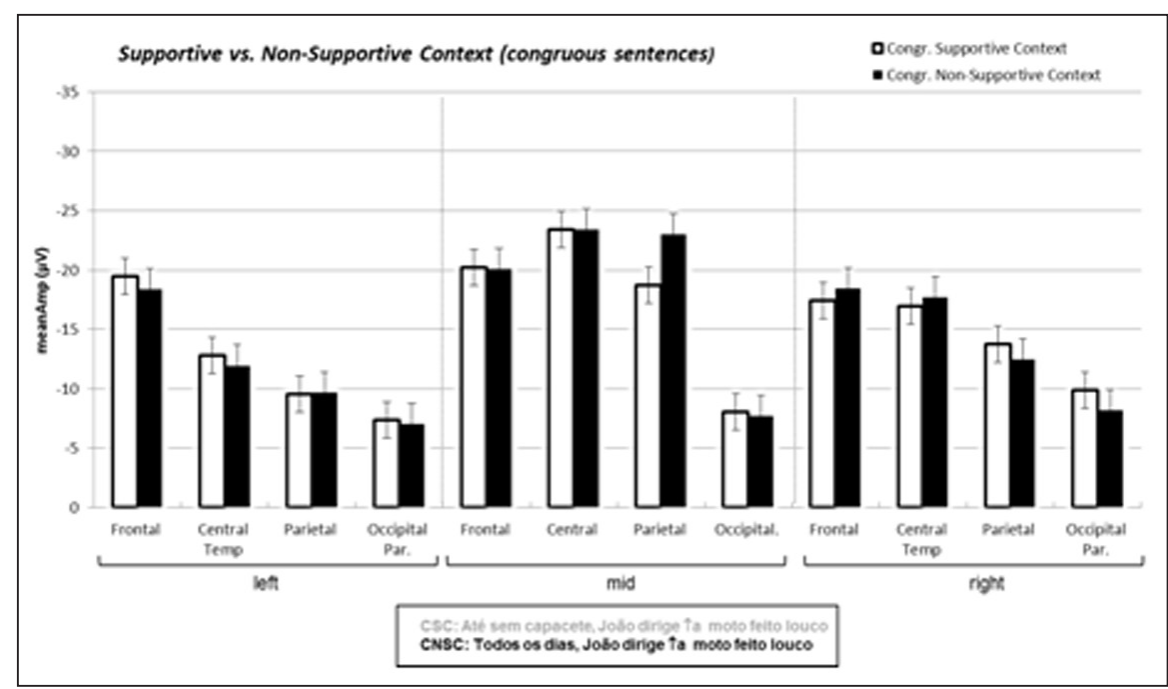

Graph 4. Mean amplitudes for supportive vs. non-suportive context for incongruous sentences

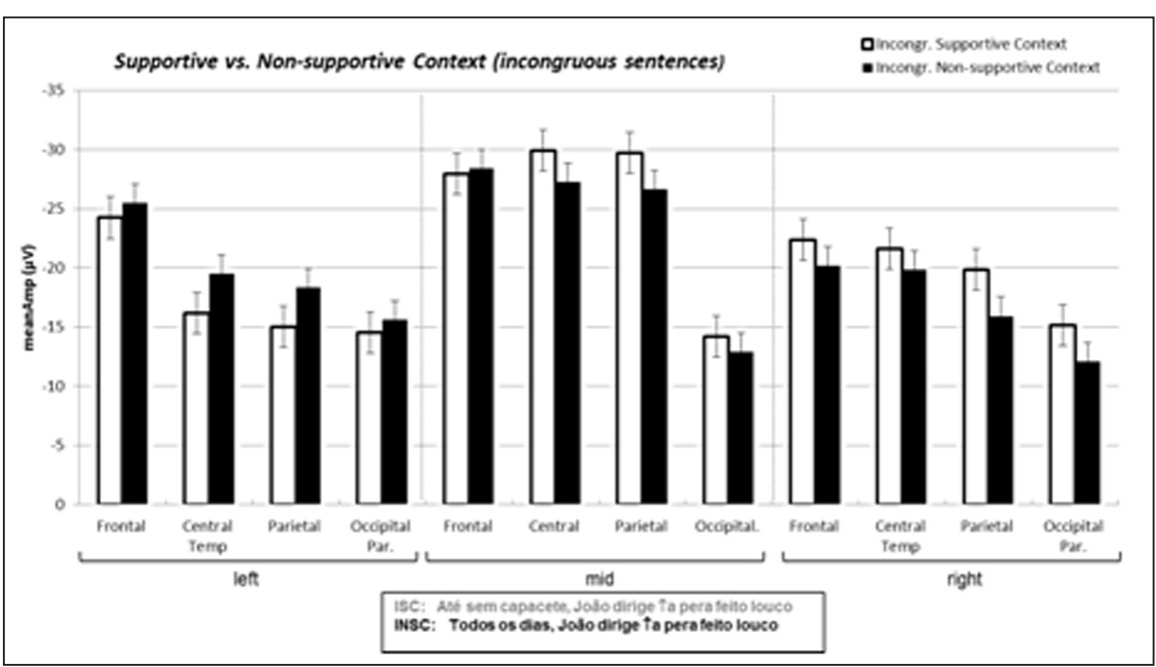


the peak latency measures $(F(1,16)=1,742, p=0,205)$, while there was the expected control effect for incongruence $(F(1,18)=17,157, p=0,001$, presenting higher amplitudes for incongruous sentences than for congruous sentences, indicative of a cognitive effort in the integration of an ill-fitting complement in the verb phrase. These effects, although present, did not affect latency measures, $F(1,16)=3,21, p=0,092$. There was no interaction between congruency and context variables (amplitude: $(\mathrm{F}(1,18)=0,589, \mathrm{p}=0,453$; latency: $\mathrm{F}(1,16)=0,22, \mathrm{p}=0,65)$. These results contradict findings in literature concerning (i) the influence of contextualized sentence frames on N400 measures; (ii) the increase of N400 amplitude for incongruous contextualized sentences in comparison to non-contextualized sentences (KUPERBERG et al., 2003; HAGOORT et al., 2004; FEDERMEIER et al., 2007; KUTAS, 2011).

Our data confirm that it is not the contextualization that modulates the N400 effects, given that incongruency effects are similar for contextualized and non-contextualized sentences, but rather that verbcomplement combinatorics affect N400 amplitudes. That is, lexical access of complement nouns is, at least initially, influenced by verb-complement relations.

Therefore, we conclude that under a tight SOA, there is no difference in the cognitive effort between congruous sentences with contextually supportive or nonsupportive adverbial adjuncts, that is, in strength (mean amplitude and latencies) as well as in distribution, these conditions present similarity. For incongruous sentences, there is also no indication that the cognitive effort for contextually supportive or non-supportive adverbial adjuncts is different.

However, there is an interesting difference in the distribution of the incongruency effect for amplitudes (and in much lesser degree also for latencies), which is driven by the relative strength of the response to incongruous contextualized vs. non-contextualized sentences. Whereas non-contextualized incongruous sentences generate a relatively larger response in the left hemisphere, contextualized incongruous sentences generate a relatively larger response in midline regions.

This might indicate that integration processes within the VP, when frustrated (such as is the case for incongruous sentences), look to subsequently, associate information from outside of the local scope (incrementally processed information, or co-activated lexical representations by way of a priming effect from other words in the sentence) to other types of knowledge (extra-linguistic in nature). Naturally, when little relevant information is available (such as in non-contextualized sentences), the wrap up of the N400 effect can unfold within the language dominant left hemisphere.
On the other hand, if the information that becomes available after immediate integration attempts is rich in contextual content, processes may seek to connect with associative areas; hence the signal is picked up strongest at midline sites, and more evenly distributed over left and right hemispheres. If SOAs are extended to longer intervals, the typical N400 congruency effect is strongest in central and parietal areas and is strongly modulated by context constraint, perhaps this reflects the fact that longer SOAs tap into posterior processes that engage the association and integration between linguistic and extralinguistic knowledge.

The objective of the ERP experiment was to tease apart the underlying functionalities of the N400 component and it successfully displayed the specific nature of the N400 wheeling around the verb- complement relations. Encompassing information in the adjunct did not affect the N400 component. Further image studies are required to assess the distribution differences between the congruent and the incongruent stimuli.

\section{References}

FEDERMEIER, Kara D.; KUTAS, Martha. A Rose by Any Other Name: Long-Term Memory Structure and Sentence Processing. Journal of Memory and Language, v. 41, p. 469-495, 1999. http://dx.doi.org/10.1006/jmla.1999.2660

FEDERMEIER, Kara D. et al. Multiple effects of sentential constraint on word processing. Brain research, 1146, p. 75-84, 2002. http://dx.doi.org/10.1016/j.brainres.2006.06.101

FRANÇA, Aniela Improta. Concatenações lingüisticas: estudo de diferentes módulos cognitivos na aquisição e no córtex. Rio de Janeiro, 2002. Tese (Doutorado em Linguística) - Faculdade de Letras, Universidade Federal do Rio de Janeiro, 2002.

FRANÇA, Aniela Improta et al. A neurofisiologia do acesso lexical: palavras em português. Veredas Online - Psicolinguística, Juiz de Fora, v. 2, p. 34-49, 2008.

FRANÇA, Aniela Improta; MANHÃES, Aline Gesuladi; SOTO, Marije. Modulando o N400 através da incongruência semântica estabelecida pela relação antecedente-pronome. Linguística, Rio de Janeiro, v. 2, p. 221-238, 2012.

FRANKLIN, Michael. S. et al. Semantic priming modulates the N400, N300, and N400RP. Clinical Neurophysiology, v. 118, p. 1053-1068, 2007.

FRIEDERICI, Angela D. The brain basis of language processing: from structure to function. Physiological reviews, v. 91 , n. 4, p. 1357-1392, 2011. http://dx.doi.org/10.1152/physrev. 00006.2011

FRIEDERICI, A. D. The cortical language circuit: from auditory perception to sentence comprehension. Trends in cognitive sciences, v. 16, n. 5, p. 262-268, 2012. Available from: <http:// www.ncbi.nlm.nih.gov/pubmed/22516238> (access: May 25, 2013). http://dx.doi.org/10.1016/j.tics.2012.04.001

GOMES, Juliana Novo; FRANÇA, Aniela Improta. The ample semantic scope of minute language computations: an ERP study of words in Portuguese. Revista da Anpoll, v. 34, n. 2, p. 132-161, 2013. 
HAGOORT, Pieter et al. Integration of word meaning and world knowledge in language comprehension. Science, New York, v. 304, n. 5669, p. 438-441, 2004. Available from: <http://www. ncbi.nlm.nih.gov/pubmed/15031438> (access: May 25, 2013).

JASPER, H. The ten-twenty electrode system of the International Federation. Electroencephalography and Clinical Neurophysiology, v. 10, p. 371-375, 1958.

KUPERBERG, Gina R.; HOLCOMB, Phillip J., SITNIKOVA, Tatiana. Distinct patterns of neural modulation during the processing of conceptual and syntactic anomalies. Journal of Cognitive Neuroscience, v. 15, n. 2, p. 272-293, 2003. Available from: <http://www.ncbi.nlm.nih.gov/pubmed/12676064>.

KUTAS, Martha; FEDERMEIER, Kara D.Thirty Years and Counting: Finding Meaning in the N400 Component of the Event-Related Brain Potential (ERP). Annual Review of Psychology, v. 62, p. 621-647, agosto 2011.

KUTAS, Marta; HILLYARD, Steven A. Reading Senseless Sentences: Brain Potentials Reflect Semantic Incongruity. Science, v. 207, p. 203-207, 1980. http://dx.doi.org/10.1126/ science. 7350657

KUTAS, Martha; van PETTEN, Cyma. Event-Related Brain Potential Studies of Language. In: COLES, M. G. H.; ACKLES, P.K.; JENNINGS, J. R. (Eds.). Advances in Psychophysiology. Greenwich, Connecticut: JAI Press, Inc., 1988. p. 139-187.
KUTAS, Martha; FEDERMEIER, Kara D. Electrophysiology reveals semantic memory use in language comprehension. Trends in cognitive sciences, v. 4, p. 463-470, 1988. http:// dx.doi.org/10.1016/S1364-6613(00)01560-6

LAU, Ellen et al. A lexical basis for N400 context effects: Evidence from MEG. Brain \& Language, v. 111, n. 3, p. 161-172, 2009. http://dx.doi.org/10.1016/j.bandl.2009.08.007

LAU, Ellen; PHILLIPS, Collin; POEPPEL, David. A cortical network for semantics: (de)constructing the N400.Nature reviews. Neuroscience, v. 9, n. 12, p. 920-933, 2008. Available from: <http://www.ncbi.nlm.nih.gov/pubmed/19020511> (access: May 24, 2013). http://dx.doi.org/10.1038/nrn2532

LUCK, Steven. Introduction to the Event-Related Potential Technique. Cambridge: MIT Press, 2005.

POEPPEL, David. Pure word deafness and the bilateral processing of the speech code. Cognitive Science, v. 25, n. 5, p. 679-693, 2001. http://doi.org/10.1207/s15516709cog2505_3.

Recebido: 31 de agosto de 2014

Aprovado: 08 de novembro de 2014

Contatos: marijesoto@hotmail.com aniela@gmail.com alinegesualdi@gmail.com juliana.n.gomes@colorado.edu 